\title{
Muscle fitness and its association with body mass index in children and adolescents aged 7-18 years in China: a cross-sectional study
}

Huijing He $e^{1,2}$, Li Pan ${ }^{1,2}$, Jianwei Dư ${ }^{3}$, Feng Liư , Yuming Jin ${ }^{3}$, Jingang Ma ${ }^{4}$, Li Wang ${ }^{1,2}$, Pengben Jia ${ }^{3}$, Zhiping $\mathrm{Hu}^{4}$ and Guangliang Shan ${ }^{1,2^{*}}$ (D)

\begin{abstract}
Background: The present study was the first one aimed to investigate the current muscle fitness and its associated factors among children and adolescents in mainland China.

Methods: From Nov 2013 to Jul 2014, 2283 children and adolescents aged 7-18 were recruited in Hainan and Shaanxi Provinces in China by cross-sectional design. Information on anthropometry and muscle fitness, measured by hand grip strength (GS), vertical jump (VJ) and sit-and-reach (SR), were collected. Analysis of covariance was performed by using general linear regression models to identify the association between BMI and muscle fitness.

Results: The means of GS, VJ and SR in boys were $22.30 \pm 11.55 \mathrm{~kg}, 22.93 \pm 6.80 \mathrm{~cm}$ and $3.58 \pm 7.31 \mathrm{~cm}$, respectively, and in girls were $16.61 \pm 6.87 \mathrm{~kg}, 18.11 \pm 4.08 \mathrm{~cm}$ and $7.18 \pm 5.72 \mathrm{~cm}$, respectively. GS (from $8.26 \mathrm{~kg}$ in the 7-8-yearold group to $27.91 \mathrm{~kg}$ in the 17-18 group) and SR (from $1.75 \mathrm{~cm}$ in the-8-year-old group to $10.12 \mathrm{~cm}$ in the 17-18 group) increased with age (both $p$ for trend $<0.001$ ). Boys had higher GS and VJ, but significantly lower SR than girls in each age group $(p<0.001)$. After adjusting for age, sex, residential areas and study regions, GS increased with elevated BMI (compared with normal weight group, the regression coefficient for thinness and overweight/ obesity were $-2.997(95 \% \mathrm{Cl}:-3.693$ to -2.301$)$ and 1.220 (95\%Cl: 0.285 to 2.155$)$, respectively. With the $p$ values less than 0.001 and 0.011 , respectively). For VJ, there was no difference found between normal weight group and overweight/obesity group $(p=0.550)$, but the thinness group had the lowest performance (regression coefficient $=$ $-2.681,95 \% \mathrm{Cl}$ from -3.965 to $-1.397, p<0.001)$. For SR, compared with normal weight group, the regression coefficients for thinness and overweight/obesity were $-1.313(95 \% \mathrm{Cl}:-2.228$ to -0.399$)$ and $-1.623(95 \% \mathrm{Cl}:-3.216$ to -0.030 ) respectively, both $p<0.05$.
\end{abstract}

Conclusions: Increased body weight may have a positive association with isometric muscle strength measured by grip strength, but a negative one with strength of lifting the body. Sex difference was also found in the performance of flexibility.

Keywords: Muscle fitness, Body mass index, Children, Adolescents, Health, China

\footnotetext{
*Correspondence: guangliang_shan@163.com

'Department of Epidemiology and Statistics, Institute of Basic Medical Sciences, Chinese Academy of Medical Sciences, 5 Dongdansantiao, Dongcheng District, Beijing 100005, China

2Department of Epidemiology and Statistics, School of Basic Medicine, Peking Union Medical College, 5 Dongdansantiao, Dongcheng District, Beijing 100005, China

Full list of author information is available at the end of the article
}

(c) The Author(s). 2019 Open Access This article is distributed under the terms of the Creative Commons Attribution 4.0 International License (http://creativecommons.org/licenses/by/4.0/), which permits unrestricted use, distribution, and reproduction in any medium, provided you give appropriate credit to the original author(s) and the source, provide a link to the Creative Commons license, and indicate if changes were made. The Creative Commons Public Domain Dedication waiver (http://creativecommons.org/publicdomain/zero/1.0/) applies to the data made available in this article, unless otherwise stated. 


\section{Background}

Muscle fitness is an important aspect of physical fitness and health status [1]. It can be defined as the maximal force or tension that a muscle or a group of muscles could generate at a specified velocity [2]. A decrease of muscle fitness may result in functional limitations [3] and musculoskeletal components were found inversely associated with metabolic risk $[4,5]$. There was substantial evidence that indicated that youth muscle fitness (MF) was an important marker of cardiovascular disease (CVD) risk factors [6-8], as well as CVD events in children and adolescents [9]. Therefore, MF in juveniles may be a valuable assessor of health risk factors.

Vertical jump (VJ) has been commonly used to assess muscular power in the lower limbs and can often provide information regarding functional capacity [10]. There were previous studies that investigated the relationship between vertical jump and anthropometric characteristics or established normative data [2, 11-13]. However, because all of these studies were not conducted in Asian children or adolescents, data on youths in mainland China is sparse.

The sit-and-reach (SR) test is a field test used to measure hamstring and lower back flexibility [14]. Hand grip strength (GS) is a measurement for upper body muscle strength [15]. GS can be used as an indicator for an individual's general muscle strength [1]. Vertical jump, hand grip strength and sit-and-reach were considered indexes for muscle fitness in the present study. Since the ability to perform short-term maximal exercise varies between populations, it is important to investigate population specific data on MF.

Age, gender, morphological and metabolic factors have been found as determinants in anaerobic performance [16]. Moreover, there were previous studies that suggested that body mass index (BMI) was associated with muscle fitness $[17,18]$, and that increasing weight may be related to greater performance on muscle fitness tests. Geographical, socioeconomic and sexual disparities in health-related physical fitness and BMI were also observed $[19,20]$. Child overweight and obesity has risen in middle- and low- income countries [21]. Accompanied with rapid socioeconomic progress in China in the past decades, the prevalence of overweight and obesity in children and adolescents also increased and was believed to be associated with urbanization [22]. However, data on MF and its relationship with BMI in Chinese children and adolescents is sparse.

Therefore, the objective of this study was to use the data derived from a community-based cross-sectional study to provide information on the status of MF, as well as its relationship with body weight, measured by BMI, among children and adolescents aged $7-18$ by gender and age groups. To the best of our knowledge, this was the first study in mainland China to explore the current situation of MF performance and its relationship with BMI in children and adolescents.

\section{Methods \\ Study design}

Cross-sectional design was used in the present study. From Nov 2013 to Jul 2014, a multi-stage stratified cluster sampling method was used to select subjects (see Fig. 1: The flow-chart of the sampling method). In the first stage, Shaanxi Province in Northwest China and Hainan Province in South China were selected. In the second stage, two cities and two counties were selected from each province based on their economic status measured by local gross domestic product (GDP). In the third stage, districts were selected from cities, and rural townships were selected from counties. In the final stage, communities were selected from districts in urban areas, whereas villages were selected from townships in rural areas. All children and adolescents lived in the selected districts and villages were all invited to participant in the study. To guarantee a representative sample, after each day's field work, the age-, sex- and urbanization-stratified participants proportion would be calculated and compared with the local population proportion. The enrollment proportion for the next day's participants would be correspondingly modified if there was a slight deviation.

\section{Subjects}

A total of 2283 children and adolescents living in Hainan (South China) and Shaanxi (Northwest China) Province participated in the study. Children and adolescents aged 7-18 who were residents in the selected areas and who had lived in the current residence for at least 1 year were eligible to participate. Ethical approval was obtained from the Bioethical Committee of Institute of Basic Medical Sciences, Chinese Academy of Medical Sciences. All parents of the participants provided written informed consent before the survey.

\section{Procedures}

A standard questionnaire was developed to conduct face-to-face interview. Demographic information, such as sex, age and residential areas, was obtained through the parents of the subjects. Physical examinations were conducted and collected information on anthropometry and MF. Anthropometry included stature and weight. Measurements on MF consisted of hand grip strength, vertical jump and sit-and-reach. Before the survey, all interviewers and technicians completed a training program that guaranteed their ability for using specific tools and methods.

Stature was measured to nearest $0.1 \mathrm{~cm}$ using a fixed stadiometer. Weight was measured by body composition 


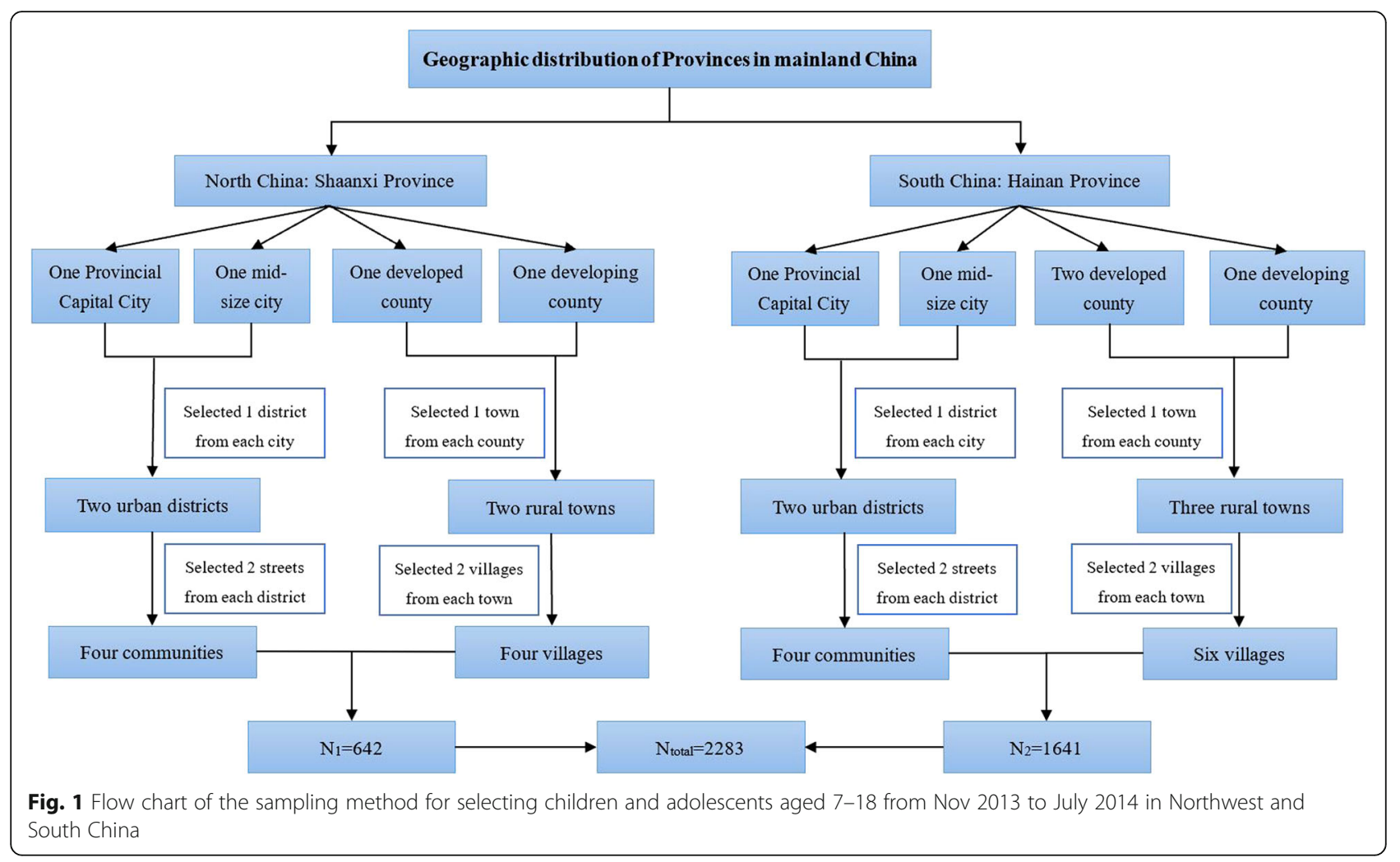

analyzer (TANITA BC-420, Japan), with the accuracy to the decimal level. During the anthropometric measurements, participants wore light clothing and were barefoot. BMI was calculated as weight in kilograms divided by the square of stature in meters $\left(\mathrm{kg} / \mathrm{m}^{2}\right)$.

Vertical jump was evaluated by the Squat Jump (SJ). During the SJ, participants were instructed to sink and to hold a squat position for $3 \mathrm{~s}$. On the count of three, subjects were asked to jump as high as possible. Jump with no sinking or countermovement prior to the execution was considered as a successful try. Hand grip strength of the predominant hand of each participant was measured two times using Jamar Hydraulic Hand Evaluation Kit (JAMAR, UK) in a standing position. In the sit-and-reach test, subjects were examined wearing light clothes and no shoes. The test was performed twice consecutively, with $30 \mathrm{~s}$ rest between tests. Subjects assumed a long-sitting position on the board, kept the knees fully extended and feet dorsiflexed and positioned flat against the foot platform. The fingertips were placed together and adjacent to the block that laid along the scale. The subject's hands pushed the block forward the scale as far as possible and the scale measurement was recorded. Vertical jump, hand grip strength and sit-and-reach tests were all requested to perform twice and the larger one of each item was analyzed.

Thinness, normal weight, overweight and obesity were defined according to World Health Organization
(WHO) 's criteria for children and adolescents 5-19 years old: thinness was BMI-for-age lower than 2 standard deviations below the WHO Growth Reference median; overweight was BMI-for-age greater than 1 standard deviation above the WHO Growth Reference median; and obesity was greater than 2 standard deviations above the WHO Growth Reference median [23].

\section{Statistical analyses}

All statistical procedures were performed using SAS 9.4 (SAS Institute Inc. Cary, NC, USA). Summary results were presented as mean (standard deviation, SD) for continuous data and number (percentage, \%) for categorical data. Data from boys and girls were analyzed separately. Mean, standard deviation (SD), median and interquartile range were reported for all MF tests by gender and age groups because of the non-normal distribution of the results.

Chi-square tests or Student's t-test (or Wilcoxon sign test) were used to compare characteristics of participants in the analytic sample $(n=2283)$. Comparison among age groups was analyzed using ANOVA or Kruskal-Wallis test. Cochran-Armitage test was used to analyze the trend among age groups and BMI groups. As it was expected that the measures of MF in this study were possibly correlated, we further calculated correlation coefficients of the three indexes for MF using Pearson and Spearman correlation analyses. Since there were 
limited number of obesity in both boys and girls, obesity was integrated with overweight as one category, presented as overweight/obese in the results section.

Two-way ANCOVA was performed by using general linear regression models (GLMs) to identify the association between BMI and muscle fitness (GS, VJ and SR). In the sensitivity analyses, quantile regression models were used to compare the results yielded by GLM. Sub-group analyses were conducted within age-groups to detect the possible role of age on the association between BMI and muscle fitness.

\section{Results}

\section{Demographic and anthropometric characteristics of participants}

The analyses for this study were based on 2283 children and adolescents (1032 boys and 1251 girls) aged 7-18 who participated in the muscle fitness tests and were classified in three BMI categories. The demographic and anthropometric characteristics stratified by sex were presented in Table 1. Boys had a higher average age and proportion of living in rural areas, and were more recruited in Shaanxi Provinces than that of girls.

\section{The distribution of body mass index and its associated factors}

$82.29 \%$ of boys and girls were normal weight, $12.66 \%$ were underweight and $7.05 \%$ were overweight/obese. The prevalence of underweight, normal weight and overweight/obesity in boys were $14.24,75.78$ and $9.98 \%$, respectively, and in girls were $11.35,84.01$ and $4.64 \%$, respectively. The sex-specific prevalence of thinness and overweight/obesity were presented in Additional file 1: Table S1. The results of multi-variable logistic regression models indicated that, boys $(\mathrm{OR}=1.371,95 \% \mathrm{CI}: 1.065-$ 1.764), urban residence $(\mathrm{OR}=0.447$, 95\% CI: $0.336-$ $0.594)$ and living in Shaanxi Province $(\mathrm{OR}=0.534,95 \%$ CI: 0.387-0.737) were associated with thinness (reference group $=$ normal weight). This participants showed that who were male, living in urban areas and recruited

Table 1 Baseline characteristics of children and adolescents. N and percentage (\%) for categorical data and mean and standard deviation for continuous data

\begin{tabular}{|c|c|c|c|c|c|c|}
\hline \multirow[b]{2}{*}{ Age $^{*}$, year } & \multicolumn{2}{|c|}{ Boys $(n=1032)$} & \multicolumn{2}{|c|}{ Girls $(n=1251)$} & \multicolumn{2}{|c|}{ Total $(n=2283)$} \\
\hline & 13.36 & 3.11 & 13.77 & 3.36 & 13.58 & 3.26 \\
\hline \multicolumn{7}{|l|}{ Age-group $^{*}$} \\
\hline $7-8$ & 73 & 7.07 & 94 & 7.51 & 167 & 7.31 \\
\hline 9 & 97 & 9.40 & 126 & 10.07 & 223 & 9.77 \\
\hline 10 & 115 & 11.14 & 128 & 10.23 & 243 & 10.64 \\
\hline 11 & 111 & 10.76 & 116 & 9.27 & 227 & 9.94 \\
\hline 12 & 119 & 11.53 & 104 & 8.31 & 223 & 9.77 \\
\hline 13 & 103 & 9.98 & 80 & 6.39 & 183 & 8.02 \\
\hline 14 & 78 & 7.56 & 62 & 4.96 & 140 & 6.13 \\
\hline 15 & 74 & 7.17 & 98 & 7.83 & 172 & 7.53 \\
\hline 16 & 82 & 7.95 & 140 & 11.19 & 222 & 9.72 \\
\hline 17 & 78 & 7.56 & 151 & 12.07 & 229 & 10.03 \\
\hline 18 & 102 & 9.88 & 152 & 12.15 & 254 & 11.13 \\
\hline \multicolumn{7}{|l|}{ Residential areas ${ }^{*}$} \\
\hline Urban & 514 & 49.81 & 702 & 56.12 & 1216 & 53.26 \\
\hline Rural & 516 & 50.00 & 549 & 43.88 & 1065 & 46.65 \\
\hline \multicolumn{7}{|l|}{ Study sites ${ }^{*}$} \\
\hline Shaanxi Province & 333 & 32.27 & 309 & 24.70 & 642 & 28.12 \\
\hline Hainan Province & 699 & 67.73 & 942 & 75.30 & 1641 & 71.88 \\
\hline Stature $^{*}, \mathrm{~cm}$ & 152.55 & 16.13 & 148.67 & 12.19 & 150.43 & 14.24 \\
\hline Weight ${ }^{*}, \mathrm{~kg}$ & 42.11 & 13.87 & 39.2 & 10.63 & 40.51 & 12.28 \\
\hline $\mathrm{BMI}, \mathrm{kg} / \mathrm{m}^{2}$ & 17.58 & 3.16 & 17.37 & 2.78 & 17.47 & 2.96 \\
\hline Vertical jump*, cm & 22.93 & 6.80 & 18.11 & 4.08 & 20.18 & 5.92 \\
\hline Hand grip strength ${ }^{*}, \mathrm{~kg}$ & 22.30 & 11.55 & 16.61 & 6.87 & 19.17 & 9.69 \\
\hline Sit-and-reach ${ }^{*}, \mathrm{~cm}$ & 3.58 & 7.31 & 7.33 & 7.18 & 5.72 & 7.47 \\
\hline
\end{tabular}

" $p<0.05$ for the comparison between boys and girls 
in Shaanxi Province were more likely to be overweight/ obese, with ORs (95\% CI) of 2.260 (1.594-3.203), 3.118 (2.164-4.492) and 3.668 (2.615-5.202), respectively. In contrast, age was found inversely associated with overweight/obesity with the OR $(95 \%$ CI) of 0.816 (0.7690.865) (Additional file 1: Table S5).

\section{Performance of muscle fitness and its associations with body mass index \\ Performance on the hand grip strength test}

The means of GS in boys and girls were $22.30 \pm 11.55 \mathrm{~kg}$ and $16.61 \pm 6.87 \mathrm{~kg}$, respectively. Positive age dependent linear trends were observed in both sexes (Table 2, both $p<0.001)$. The means of GS increased from $8.26 \mathrm{~kg}$ in the 7-8-year-old group to $27.91 \mathrm{~kg}$ in the $17-18$-year-old group. Before adjusting for age, the normal weight group had the highest GS in both sexes. However, the age-, urbanization-and geographic-adjusted means of GS indicated a significantly increasing trend of GS with elevated BMI categories, from $18.11 \mathrm{~kg}$ to $24.06 \mathrm{~kg}$ in boys and $14.39 \mathrm{~kg}$ to $18.88 \mathrm{~kg}$ in girls, in which the overweight/obese group had the highest GS in both sexes. The comparisons of the adjusted means of GS among BMI groups were presented separately by sex in Fig. 2a. GLMs also supported the idea that increased BMI was positively associated with GS performance (Table 3 ). After adjusting for age, sex, residential areas and study regions, BMI was found associated with GS (Table 3). Before BMI was considered in the GLM, study regions (Shaanxi Province) was found associated with GS $(P=$ $0.002)$, but the association became nonsignificant after adjustment for BMI $(P=0.086$, Table 3$)$.

\section{Performance on the vertical jump test}

Similar to GS, sex difference was also found in VJ performance, where the means of vertical jump in boys $(22.93 \pm 6.80 \mathrm{~cm})$ were higher than that of girls $(18.11 \pm$ $4.08 \mathrm{~cm}$ ). Different from hand grip strength, the variations of VJ among age groups were not as much as that of GS, ranging from $17.74 \mathrm{~cm}$ in the youngest group to $21.56 \mathrm{~cm}$ in the 15-16-year-old group. VJ performance varied by age groups in both sex (both $p<0.01$ ). But for boys, VJ seemed increased with age, and for girls, the VJ peak was in the 11-14 age group. Boys had greater performance on VJ than girls in the age groups beyond 10 years old (Table 2).

In contrast with GS, overweight/obese youth in both boys and girls had the lowest value of VJ, the age-, urbanization-and geographic-adjusted means of which were $19.93 \mathrm{~cm}$ and $17.32 \mathrm{~cm}$, respectively (Fig. 2b). The linear regression model also revealed that BMI categories were inversely associated with VJ (Table 3). Moreover, sex disparity was found in the relationship between $\mathrm{VJ}$ and BMI when comparing the adjusted means of MF

Table 2 The means and medians of hand grip strength, vertical jump and sit-and-reach in age groups across sex among children and adolescents aged 7-18 in China, 2014

\begin{tabular}{|c|c|c|c|c|c|c|c|c|c|c|c|c|c|c|c|}
\hline \multirow[t]{2}{*}{ Age } & \multirow[b]{2}{*}{$n$} & \multicolumn{4}{|l|}{ GS (kg) } & \multirow[b]{2}{*}{$n$} & \multicolumn{4}{|l|}{$\mathrm{VJ}(\mathrm{cm})$} & \multirow[b]{2}{*}{$n$} & \multicolumn{4}{|c|}{$\mathrm{SR}(\mathrm{cm})$} \\
\hline & & Mean & SD & Median & $\mathrm{IQR}$ & & mean & SD & Median & IQR & & mean & SD & Median & $\mathrm{IQR}$ \\
\hline \multicolumn{16}{|c|}{ Boys } \\
\hline $7-8$ & 73 & 9.40 & 2.49 & 10.00 & 3.00 & 42 & 18.69 & 3.22 & 18.65 & 5.00 & 45 & 0.20 & 5.66 & -0.60 & 7.70 \\
\hline $9-10$ & 208 & 11.88 & 3.29 & 12.00 & 4.00 & 142 & 18.58 & 4.09 & 18.25 & 6.10 & 149 & 0.60 & 5.79 & 1.50 & 7.40 \\
\hline $11-12$ & 223 & 15.62 & 5.19 & 15.00 & 6.00 & 157 & 21.46 & 5.52 & 21.30 & 7.60 & 165 & 1.01 & 5.88 & 1.80 & 7.80 \\
\hline $13-14$ & 178 & 24.29 & 7.19 & 24.00 & 10.00 & 119 & 23.81 & 6.23 & 22.90 & 7.70 & 122 & 3.91 & 6.86 & 3.90 & 8.80 \\
\hline $15-16$ & 155 & 32.79 & 7.61 & 32.00 & 9.00 & 93 & 25.76 & 7.17 & 25.30 & 9.30 & 94 & 7.89 & 7.52 & 7.65 & 10.50 \\
\hline $17-18$ & 179 & $36.91+$ & 6.75 & 36.00 & 9.00 & 119 & 28.47 & 7.08 & 28.40 & 9.10 & 120 & 8.34 & 7.51 & 8.10 & 8.55 \\
\hline Overall & 1016 & 22.30 & 11.55 & 19.00 & 20.00 & 672 & 22.93 & 6.80 & 21.95 & 9.05 & 695 & 3.58 & 7.31 & 3.30 & 9.30 \\
\hline \multicolumn{16}{|l|}{ Girls } \\
\hline $7-8$ & 93 & $7.36^{*}$ & 2.14 & 8.00 & 2.00 & 42 & 17.06 & 4.00 & 16.50 & 5.10 & 67 & $2.79^{*}$ & 5.19 & 2.50 & 6.40 \\
\hline $9-10$ & 252 & $9.70^{*}$ & 3.08 & 10.00 & 4.00 & 142 & 17.48 & 4.08 & 17.00 & 5.50 & 183 & $3.48^{*}$ & 5.75 & 3.40 & 7.20 \\
\hline $11-12$ & 218 & $14.47^{*}$ & 4.80 & 14.00 & 7.00 & 157 & $19.15^{*}$ & 4.03 & 19.20 & 4.50 & 162 & $4.72^{*}$ & 6.19 & 4.35 & 7.30 \\
\hline $13-14$ & 142 & $18.54^{*}$ & 4.47 & 18.00 & 6.00 & 119 & $18.51^{*}$ & 4.13 & 18.35 & 5.65 & 102 & $7.48^{*}$ & 6.81 & 7.85 & 9.60 \\
\hline $15-16$ & 238 & $20.79^{*}$ & 4.53 & 21.00 & 6.00 & 93 & $18.11^{*}$ & 4.09 & 18.00 & 5.20 & 180 & $10.34^{*}$ & 6.70 & 10.45 & 8.45 \\
\hline $17-18$ & 302 & $22.58^{*}$ & 4.76 & 22.00 & 5.00 & 119 & $17.98^{*}$ & 3.96 & 17.95 & 5.80 & 236 & $11.02^{*}$ & 6.89 & 11.80 & 9.25 \\
\hline Overall & 1245 & $16.61^{*}+$ & 6.87 & 17.00 & 11.00 & 672 & $18.11^{*}$ & 4.08 & 18.00 & 5.50 & 930 & $7.33^{*}+$ & 7.18 & 7.20 & 9.80 \\
\hline
\end{tabular}

$S D$ standard deviation, $I Q R$ interquartile range

${ }^{*} p<0.001$ for the comparison between boys and girls

$t p<0.001$ for the linear trend tests using Cochran-Armitage method 


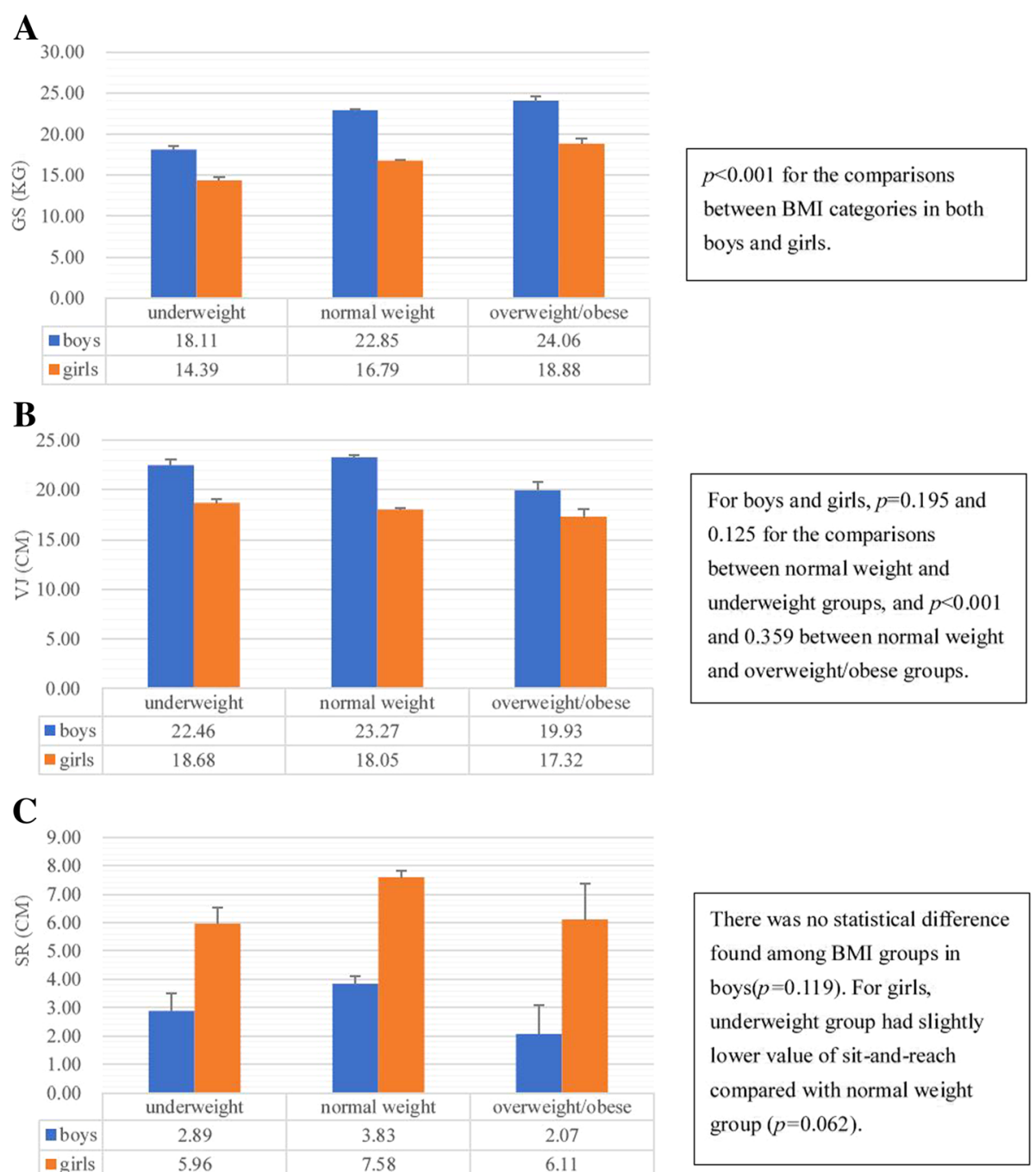

Fig. 2 Adjusted means and standard errors of hand grip strength, vertical jump and sit-and-reach across sex and BMI categories in children and adolescents aged 7-18 in China. Adjusted covariates included age, urbanization and geographic areas

performance. In boys, underweight and normal weight groups had greater VJ values $(22.46 \mathrm{~cm}$ and $23.27 \mathrm{~cm}$, respectively) than overweight/obese group $(19.93 \mathrm{~cm})$ (both $p<0.001$ ), but no difference between underweight and normal weight children and adolescents (both $p$ values more than 0.1, see Fig. 2b). However, in girls, the VJ performance had no statistical difference among the three BMI groups (all $p>0.05$, Fig. 2b).

\section{Performance on the sit-and-reach test}

Significant sex difference was observed on the performance of sit-and-reach test. The means of SR in boys and girls were $3.58 \mathrm{~cm}$ and $7.33 \mathrm{~cm}$, respectively. In every age group, girls had higher SR value than that of the boys (Table 2). Similar to GS, there was an increasing trend with age in both sexes $(p<0.001)$. The GLM indicated that lean youth may have lower value on SR performance.
The age-, urbanization-and geographic-adjusted means of SR in each BMI category, stratified by sex, also revealed a positive association between BMI and SR performance, with an exception of no statistical significance in male youth.

\section{The correlation among muscle strength tests}

The correlation analyses suggested that all three MF indexes had significant mutual correlations (all $p<0.01$ ) in both sexes. In boys, GS and VJ had the strongest correlation. By contrast, in girls, GS and VJ seemed to have a much weaker correlation, while still being statistically significant $(p=0.001)$. Details were presented in Fig. 3.

Furthermore, we compared the adjusted means of VJ in GS quartile groups. Similar comparisons of SR were also made to study the relationships among these three muscle fitness tests. Consistent with the correlation 
Table 3 The association between BMI and hand grip strength, vertical jump and sit-and-reach in children and adolescents aged $7-$ 18 in China, 2014

\begin{tabular}{|c|c|c|c|c|c|c|c|c|c|c|}
\hline \multirow[t]{2}{*}{ Hand grip strength } & \multicolumn{5}{|c|}{ Model $1^{\text {a }}$} & \multicolumn{5}{|l|}{ Model 2} \\
\hline & \multirow{2}{*}{$\begin{array}{l}B \\
2.253\end{array}$} & \multirow{2}{*}{$\begin{array}{l}S E \\
0.038\end{array}$} & \multicolumn{2}{|l|}{$95 \% \mathrm{Cl}$} & \multirow{2}{*}{$\frac{p}{<0.001}$} & \multirow{2}{*}{$\begin{array}{l}B \\
2.275\end{array}$} & \multirow{2}{*}{$\begin{array}{l}S E \\
0.038\end{array}$} & \multicolumn{2}{|l|}{$95 \% \mathrm{Cl}$} & \multirow{2}{*}{$\frac{p}{<0.00}$} \\
\hline Age & & & 2.178 & 2.328 & & & & 2.200 & 2.350 & \\
\hline Sex (ref $=$ girls $)$ & 6.546 & 0.239 & 6.077 & 7.015 & $<0.001$ & 6.580 & 0.236 & 6.117 & 7.043 & $<0.001$ \\
\hline Residential areas $($ ref $=$ rural) & 0.196 & 0.255 & -0.304 & 0.695 & 0.442 & 0.203 & 0.256 & -0.704 & 0.298 & 0.427 \\
\hline Shaanxi (ref = Hainan) & 0.822 & 0.270 & 0.293 & 1.352 & 0.002 & 0.467 & 0.272 & -0.065 & 0.999 & 0.086 \\
\hline Thinness (ref $=$ normal weight) & - & - & - & - & - & -2.997 & 0.355 & -3.693 & -2.301 & $<0.001$ \\
\hline Overweight/obesity (ref = normal weight) & - & - & - & - & - & 1.220 & 0.477 & 0.285 & 2.155 & 0.011 \\
\hline \multicolumn{11}{|l|}{ Vertical jump } \\
\hline Age & 0.475 & 0.046 & 0.385 & 0.564 & $<0.001$ & 0.442 & 0.046 & 0.351 & 0.532 & $<0.001$ \\
\hline Sex $(r e f=$ girls $)$ & 5.107 & 0.267 & 4.584 & 5.631 & $<0.001$ & 5.179 & 0.267 & 4.656 & 5.701 & $<0.001$ \\
\hline Residential areas $($ ref $=$ rural) & -0.145 & 0.304 & -0.740 & 0.450 & 0.632 & 0.109 & 0.309 & -0.496 & 0.715 & 0.723 \\
\hline Thinness (ref = normal weight) & - & - & - & - & - & 0.230 & 0.385 & -0.524 & 0.985 & 0.550 \\
\hline Overweight/obesity (ref = normal weight) & - & - & - & - & - & -2.681 & 0.655 & -3.965 & -1.397 & $<0.001$ \\
\hline \multicolumn{11}{|l|}{ Sit-and-reach } \\
\hline Age & 0.998 & 0.056 & 0.888 & 1.108 & $<0.001$ & 0.981 & 0.057 & 0.870 & 1.092 & $<0.001$ \\
\hline Sex $(r e f=$ girls $)$ & -3.193 & 0.327 & -3.834 & -2.553 & $<0.001$ & -3.114 & 0.327 & -3.754 & -2.473 & $<0.001$ \\
\hline Residential areas $($ ref $=$ rural) & 0.180 & 0.371 & -0.907 & 0.548 & 0.628 & -0.177 & 0.379 & -0.921 & 0.566 & 0.640 \\
\hline Thinness (ref = normal weight) & - & - & - & - & - & -1.313 & 0.467 & -2.228 & -0.399 & 0.005 \\
\hline Overweight/obesity (ref = normal weight) & - & - & - & - & - & -1.623 & 0.813 & -3.216 & -0.030 & 0.046 \\
\hline
\end{tabular}

$B M I$ body mass index $\left(\mathrm{kg} / \mathrm{m}^{2}\right), B$ regression coefficient, $S E$ standard error of regression coefficient, $\mathrm{Cl}$ confidence interval

a Model 1: adjusted for age, sex, residential areas and study sites; Model 2: adjusted for age, sex, residential areas, study sites (if applicable) and BMI. Age was analyzed as continuous data; sex, BMl, residential areas and study sites were set as dummy variables

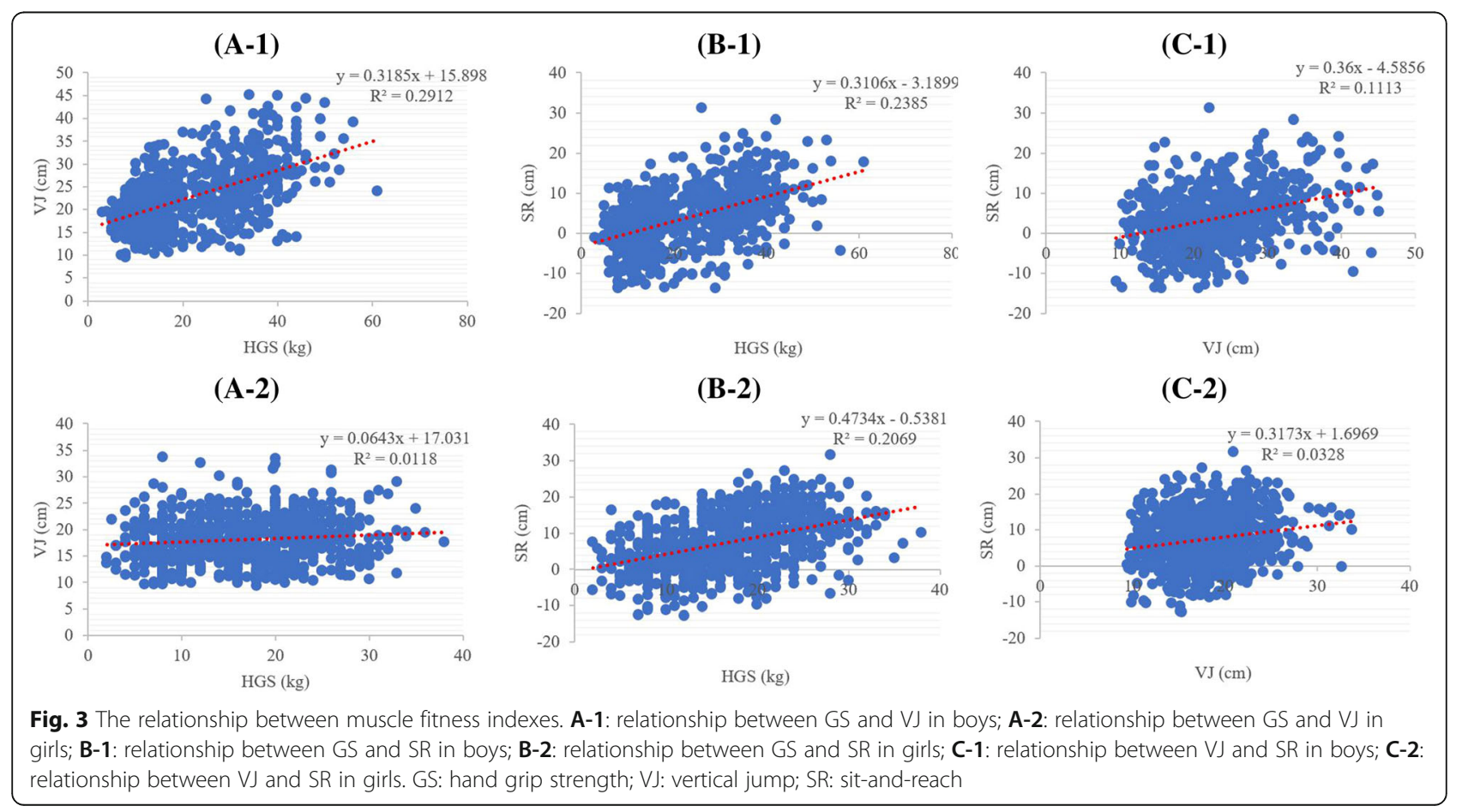


analyses, there were increasing trends for both VJ and SR with elevated GS quartiles in boys and girls $(p<$ 0.001, Additional file 1: Figure S2).

\section{Discussion}

To the best of our knowledge, this was the first study to investigate MF, measured using GS, VJ and SR, and its relationship with BMI in children and adolescents in China. As physical fitness and MF may play key roles in health in children and adolescents, it would be helpful to understand muscle function early in life and its relationship to BMI. This may be of value to understand the changes in the ability to have ideal function and health later in life.

By using a multi-stage stratified sampling method, we selected representative data reflecting BMI and MF among 7-18 years old children and adolescents. There were more participants recruited in Hainan than in Shaanxi Province because of longer recruitment time, better local government support and larger population size. Compared with Hainan, Shaanxi had more boys (51.87\% vs. $42.60 \%)$ and more participants living in rural areas $(63.08 \%$ vs. $40.27 \%)$ but their age distribution was similar $(p=0.588)$. Since we performed analyses by sex separately, and mostly adjusted by regions or urban/rural areas, the disproportion of socioeconomic characteristics in the two study sites would not cause severe bias in the study conclusions.

There were sex differences on BMI and MF in the study. Consistent with other relevant studies [20, 24], boys had higher stature in the same age group than girls, with the exception of the age groups below 10, and seemed to increase keep rising with similar rate through the 7-18 years stage. The stature of girls increased with age, but the rate fell after 11-12 years. Boys had higher prevalence of overweight/obesity than girls, especially in the ages 9-12.

China is a developing country with highly unbalanced regional development. In this study, regional and urban-rural disparities on BMI categories were identified. Compared with children and adolescents from Hainan Province, located in South China, subjects from Shaanxi Province had lower prevalence of thinness and higher prevalence of overweight/obesity. This sex and regional difference may be attributed to diversity of genomic backgrounds, physiology and environmental factors, such as different socioeconomic status (SES), nutrition status and physical exercises. Previous studies revealed that in developing countries, youths from a higher SES were more likely to be obese than youths from a lower SES $[25,26]$. Studies have also shown that youths with higher SES and from urban areas were more likely to be obese than those from lower SES and from rural areas $[27,28]$. Shaanxi province comprised more subjects from urban areas than that from Hainan, which may partially explain the higher prevalence of overweight/obesity and lower prevalence of thinness.

Based on our study, MF, except VJ, was found increased with age. In general, boys had higher GS and VJ until older age when GS and VJ values became similar to those of girls. Consistent with other studies, GS in boys accelerated specifically after the age of $12[29,30]$. Compared with US children and adolescents (with an average performance value of $26.3 \mathrm{~kg}$ in the age 7 group and $79.7 \mathrm{~kg}$ in the age 15 group in boys) [18], Chinese youths had much lower GS value. This difference may be attribute to the vast disparity of genetic background and high prevalence of physical inactivity in Chinese children and adolescents [31].

There were limited data on the relationship between $\mathrm{VJ}$ and BMI, and thus its correlation with other MF indexes. Only a few studies described the VJ performance in certain populations, such as athletes or sports players $[32,33]$. As a predictor of bone health, higher VJ may indicate a better status of bone mineral density [34]. The performance of SR, in which girls were of much greater performance than boys, indicated that girls may have better hamstring and hip flexibility [35]. Based on the result of logistic models, the regional difference disappeared after BMI was adjusted, implying that the original regional difference on MF was mainly caused by BMI disproportion between the two geographic areas.

The stratification analyses revealed that BMI may play key role in influencing MF. Increased BMI was positively associated with GS but normal weight group had the greatest performance of VJ and SR. Previous studies on US population and Taiwanese Chinese population had also observed the association between physical fitness and body weight. In Ervin's study [18] on US population aged 6-15, results found that BMI was associated with strength. Studies on Taiwanese Chinese population showed that muscle strength and physical fitness were to be found associated with obesity [17, 36, 37]. However, our study was the first one in mainland China to explore the current situation of MF and its relationship with body weight.

In the sub-group analyses, BMI was associated with VJ and SR only in relatively younger age groups (Additional file 1: Table S6), which may imply that age could modify the association between BMI and muscle fitness. Further study with larger sample size needs to be done to clarify this possible modification.

The study had some limitations: Firstly, we did not assess maturation level of the participant, which may be a factor of great influence on fitness test and BMI. Secondly, the absence of detailed information on living environments, dietary patterns and physical activity limited our study on exploring other determinants of body 
weight and MF. Thirdly, we did not measure the test-retest reliability for SR, GS and VI, and therefore we were not able to obtain the coefficient of variation for each. Fourthly, in Shaanxi Province, we only collected data on hand grip strength, which limited us to be able to study the regional difference on VJ and SR. Nonetheless, we were still able to use GS as a predictor for total muscle strength in children and adolescents [1]. The three indexes of MF were correlated with each other and the difference on GS among regions was representative to some extent to reveal geographic disparities on MF in the study population. Because dynamometer was more portable and the test of grip strength was much safer among elder population, hand grip strength test could be used as a feasible and important measurement for muscle strength in a much broader population. Lastly, we did not calculate the sampling weights because of the difficult to obtain the denominator, which was the total number of qualified participants in the survey areas. This may limit the generalizability to other studies.

\section{Conclusions}

Our study was the first study to describe the current situation of MF status assessed by GS, VJ and SR in children and adolescents in China, with representative data for further exploration in other related study fields. It also explored the relationship between MF and BMI and found that increased body weight may have a positive association with isometric muscle strength measured by grip strength, but a negative one with strength of lifting the body. Sex difference was also found in the performance of flexibility. This study may provide evidence of the role of BMI on muscle fitness for clinicians and researchers based on the increasing prevalence of childhood obesity, as well as for policy makers to develop sex-specific strategies on body weight management and muscle performance promotion among children and adolescents in China.

\section{Additional file}

Additional file 1: Table S1-1. The age and sex specific proportions of thinness, normal weight and overweight/obesity in Urban/Rural areas among participants aged 7-18, 2014. Table S1-2. The age and sex specific proportions of thinness, normal weight and overweight/obesity in different study sites among participants aged 7-18, 2014. Table S2. The age and sex specific means of hand grip strength stratified by BMI categories among children and adolescents aged 7-18, 2014. Table S3. The age and sex specific means of vertical jump stratified by BMI categories among children and adolescents aged 7-18, 2014. Table S4. The age and sex specific means of sit-and-reach stratified by BMI categories among children and adolescents aged 7-18, 2014. Table S5. The associated factors of BMI among participants aged 7-18years in China, 2014. Table S6. The association between BMI and muscle fitness in children and adolescents aged 7-18 in China, stratified by age groups, 2014. Figure S1. Arithmetical means and deviations of hand grip strength, vertical jump and sit-and reach in sexes and age groups among children and adolescents aged 7-18, stratified by BMI categories. Figure S2. the adjusted means and standard errors of vertical jump and sit-and-reach, stratified by GS quartiles, in boys and girls aged 7-18 in mainland China. Covariates included residential areas and study sites, and BMI was adjusted using the LSMEANS statement in the GLM procedure in SAS. GS: hand grip strength; VJ: vertical jump; SR: sit-and-reach; Q: quartiles of grip strength. (DOCX $667 \mathrm{~kb})$

\section{Abbreviations}

ANCOVA: Analysis of covariance; ANOVA: Analysis of variance; BMI: Body mass index; Cl: Confidence interval; CVD: Cardiovascular disease; GLM: General linear regression model; GS: Hand grip strength; MF: Muscle fitness; OR: Odds ratio; SD: Standard deviation; SR: Sit-and-reach; VJ: Vertical jump; WHO: World health organization

\section{Acknowledgements}

This study was supported by the Key Basic Research Program of the Ministry of Science and Technology of China (Grant No. 2013FY114100) and CAMS Innovation Fund for Medical Sciences (CIFMS), Grant No. 2016-I2M-2-004 and 2018-I2M-1-001. We appreciate all the participants and staff members from Hainan and Shaanxi Provincial Centers for Disease Control and Prevention. We also gratefully appreciate Yvonne Li for language editing, and Guangjin Zhu, Fen Dong, Ke Wang, Guodong Xu, Guoju Li, Haiying Gong and Yanlong Li for their efforts in the field work.

\section{Funding}

This study was supported by the Key Basic Research Program of the Ministry of Science and Technology of China (Grant No. 2013FY114100), CAMS Innovation Fund for Medical Sciences (CIFMS), Grant No. 2016-12M-2-004 and 2018-12M-1-001. The funders had no role in study design, data collection and analysis, decision to publish, or preparation of the manuscript.

\section{Availability of data and materials}

The datasets generated and/or analyzed during the current study are not publicly available due to management rules by the study funder but are available from the corresponding author on reasonable request.

\section{Authors' contributions}

Conceptualization, GS and HH; methodology, GS and HH; software, $\mathrm{HH}$; validation, GS, HH and LW; formal analysis, HH; investigation, GS, LP, JD, FL, YJ, JM, LW, PJ and ZH; resources, GS, JD and FL; data curation, HH; writing—original draft preparation, HH; writing—review and editing, $\mathrm{HH}$, LW and GS; visualization, $\mathrm{HH}$; supervision, GS and LP; project administration, GS and LP; funding acquisition, GS and HH. All authors read and approved the final manuscript.

\section{Ethics approval and consent to participate}

Ethics approval was obtained from the Bioethical Committee of Institute of Basic Medical Sciences, Chinese Academy of Medical Sciences. All participants provided written informed consent by their parents before the survey.

\section{Consent for publication}

This manuscript does not contain any individual person's data in any form.

Competing interests

The authors declare that they have no competing interests.

\section{Publisher's Note}

Springer Nature remains neutral with regard to jurisdictional claims in published maps and institutional affiliations.

\section{Author details}

'Department of Epidemiology and Statistics, Institute of Basic Medical Sciences, Chinese Academy of Medical Sciences, 5 Dongdansantiao, Dongcheng District, Beijing 100005, China. ${ }^{2}$ Department of Epidemiology and Statistics, School of Basic Medicine, Peking Union Medical College, 5 Dongdansantiao, Dongcheng District, Beijing 100005, China. ${ }^{3}$ Hainan Provincial Center for Disease Control and Prevention, Haikou 570203, Hainan 
Province, China. ${ }^{4}$ Shaanxi Provincial Center for Disease Control and Prevention, Xi'an 710054, Shaanxi Province, China.

\section{Received: 17 January 2019 Accepted: 31 March 2019} Published online: 10 April 2019

\section{References}

1. Wind AE, Takken T, Helders PJM. Is grip strength a predictor for total muscle strength in healthy children, adolescents, and young adults. Eur J Pediatr. 2010;169:281-7

2. Tounsi M, Aouichaoui C, Elloumi M, Dogui M, Tabka Z, Trabelsi Y. Reference values of vertical jumping performances in healthy Tunisian adolescent. Ann Hum Biol. 2014:42(2):117-25.

3. Takken T, Elst E, Spermon N, Helders PJM, Prakken ABJ, van der Net J. The physiological and physical determinants of functional ability measures in children with juvenile dermatomyositis. Rheumatology. 2003:42:591-5.

4. Fraser BJ, Schmidt MD, Huynh QL, Dwyer T, Venn AJ, Magnussen CG. Tracking of muscular strength and power from youth to young adulthood: longitudinal findings from the childhood determinants of adult health study. J Sci Med Sport. 2017;20(10):927-31.

5. Grontved A, Ried-Larsen M, Moller NC, Kristensen PL, Froberg K, Brage S, Andersen LB. Muscle strength in youth and cardiovascular risk in young adulthood (the European youth heart study). Br J Sports Med. 2015;49(2): 90-4.

6. Fahs CA, Heffernan KS, Ranadive S, Jae SY, Fernhall B. Muscular strength is inversely associated with aortic stiffness in young men. Med Sci Sports Exerc. 2010;42(9):1619-24.

7. Ramírez-Vélez R, Rodrigues-Bezerra D, Correa-Bautista JE, Izquierdo M, Lobelo F. Reliability of health-related physical fitness tests among Colombian children and adolescents: the FUPRECOL study. PLOS One. 2015; 10(10):e140875.

8. Mason C, Brien SE, Craig CL, Gauvin L, Katzmarzyk PT. Musculoskeletal fitness and weight gain in Canada. Med Sci Sports Exerc. 2007;39(1):38-43.

9. Timpka S, Petersson IF, Zhou C, Englund M. Muscle strength in adolescent men and risk of cardiovascular disease events and mortality in middle age: a prospective cohort study. BMC Med. 2014;12:62.

10. Bui HT, Farinas M, Fortin A, Comtois A, Leone M. Comparison and analysis of three different methods to evaluate vertical jump height. Clin Physiol Funct I. 2015;35(3):203-9.

11. Ramirez-Velez R, Correa-Bautista JE, Lobelo F, Cadore EL, Alonso-Martinez AM, Izquierdo M. Vertical jump and leg power normative data for Colombian schoolchildren aged 9-17.9 years: the FUPRECOL study. Strength Cond Res. 2017;31(4):990-8.

12. Taylor MJ, Cohen D, Voss C, Sandercock GR. Vertical jumping and leg power normative data for English school children aged 10-15 years. J Sports Sci. 2010;28(8):867-72.

13. Aouichaoui C, Trabelsi Y, Bouhlel E, Tabka Z, Dogui M, Richalet JP, Buvry AB. The relative contributions of anthropometric variables to vertical jumping ability and leg power in Tunisian children. J Strength Cond Res. 2012;26(3): 777-88.

14. Baltaci G, Un N, Tunay V, Besler A, Gerceker S. Comparison of three different sit and reach tests for measurement of hamstring flexibility in female university students. Br J Sports Med. 2003:37(1):59-61.

15. Ervin RB, Wang C, Fryar CD, Miller IM, Ogden CL. Measures of muscular strength in U.S. children and adolescents. NCHS Data Brief. 2012;2013(139):1-8.

16. Van Praagh E, Dore E. Short-term muscle power during growth and maturation. Sports Med. 2002;32(11):701-28

17. Liao Y, Chang SH, Miyashita M, Stensel D, Chen JF, Wen LT, Nakamura Y. Associations between health-related physical fitness and obesity in Taiwanese youth. J Sports Sci. 2013;31(16):1797-804.

18. Ervin RB, Fryar CD, Wang C, Miller IM, Ogden CL. Strength and body weight in US children and adolescents. Pediatrics. 2014;134:e782

19. Garber MD, Sajuria M, Lobelo F. Geographical variation in health-related physical fitness and body composition among Chilean 8th graders: a nationally representative cross-sectional study. PLoS One. 2014;9(9):e108053.

20. Zhang Y, Zhao J, Chu Z. Socioeconomic inequalities in abdominal obesity among children and adolescents in Shandong, China. Int J Cardiol. 2014; 174(3):842-3.

21. Lobstein T, Jackson-Leach R, Moodie ML, Hall KD, Gortmaker SL, Swinburn BA, James WPT, Wang Y, McPherson K. Child and adolescent obesity: part of a bigger picture. Lancet. 2015;385(9986):2510-20.
22. Zhang Y, Zhao J, Chu Z. Prevalence of overweight and obesity among children and adolescents is associated with urbanization in Shandong China. Int J Cardiol. 2014;176(3):1212-3.

23. WHO. Overweight and obesity. Available at http://www.who.int/news-room/ fact-sheets/detail/obesity-and-overweight. Accessed 24 July 2018.

24. Zhang YQ, Li H. Reference charts of sitting height, leg length and body proportions for Chinese children aged 0-18 years. Ann Hum Biol. 2015;42(3): 223-30.

25. Silva DA. Socioeconomic inequalities in abdominal obesity in Brazilian female adolescents: a national-based study. Eur J Pediatr. 2013;172(12): 1665-70.

26. Ji CY, Cheng TO. Prevalence and geographic distribution of childhood obesity in China in 2005. Int J Cardiol. 2008;131(1):1-8.

27. Zhang Y, Wang Z, Zhao J, Chu Z. Prevalence of overweight and obesity among children and adolescents in Shandong, China: urban-rural disparity. J Trop Pediatrics. 2016;62(4):293-300.

28. Liu H, Fang H, Zhao Z. Urban-rural disparities of child health and nutritional status in China from 1989 to 2006. Econ Hum Biol. 2013;11(3):294-309.

29. Ploegmakers JJ, Hepping AM, Geertzen JH, Bulstra SK, Stevens M. Grip strength is strongly associated with height, weight and gender in childhood: a cross sectional study of 2241 children and adolescents providing reference values. J Physiother. 2013;59(4):255-61.

30. Butterfield SA, Lehnhard RA, Loovis EM, Coladarci T, Saucier D. Grip strength performances by 5- to 19-year-olds. Percept Mot Skills. 2009;109(2):362-70.

31. Chen Y, Zheng Z, Yi J, Yao S. Associations between physical inactivity and sedentary behaviors among adolescents in 10 cities in China. BMC Public Health. 2014;14(1):744.

32. Wong PL, Chamari K, Dellal A, Wisloff U. Relationship between anthropometric and physiological characteristics in youth soccer players. J Strength Cond Res. 2009;23(4):1204-10.

33. Chen KT, Yang RS. Effects of exercise on lipid metabolism and musculoskeletal fitness in female athletes. World J Gastroenterol. 2004;10(1): 122-6.

34. Baptista F, Mil-Homens P, Carita Al, Janz K, Sardinha LB. Peak vertical jump power as a marker of bone health in children. Int J Sports Med. 2016;37(8): $653-8$.

35. Chillon P, Castro-Pinero J, Ruiz JR, Soto VM, Carbonell-Baeza A, Dafos J, Vicente-Rodriguez G, Castillo MJ, Ortega FB. Hip flexibility is the main determinant of the back-saver sit-and-reach test in adolescents. J Sports Sci. 2010;28(6):641-8.

36. Hsieh P, Chen M, Huang C, Chen W, Li C, Chang L. Physical activity, body mass index, and cardiorespiratory fitness among school children in Taiwan: a cross-sectional study. Int J Environ Res Public Health. 2014;11(7):7275-85.

37. Huang YC, Malina RM. Body mass index and individual physical fitness tests in Taiwanese youth aged 9-18 years. Int J Pediatr Obes. 2010;5(5):404-11.

Ready to submit your research? Choose BMC and benefit from:

- fast, convenient online submission

- thorough peer review by experienced researchers in your field

- rapid publication on acceptance

- support for research data, including large and complex data types

- gold Open Access which fosters wider collaboration and increased citations

- maximum visibility for your research: over $100 \mathrm{M}$ website views per year

At BMC, research is always in progress.

Learn more biomedcentral.com/submissions 